\title{
MUNDIALIZAÇÃO, ESTADO E POLÍTICA ECONÔMICA
}

\author{
Jorge Pessoa de Mendonça
}

Professor do Depto. de Economia da Universidade Federal do Espírito Santo; Doutorando em Economia na Universidade Paris X.

\begin{abstract}
O fenômeno da globalização é freqüentemente considerado como resultado de um processo econômico, tendo como principal conseqüência a supremacia das "leis de mercado" e o enfraquecimento do papel do Estado. A liberalização da economia e a diminuição da eficácia das políticas públicas para a promoção do desenvolvimento econômico tornam-se um imperativo incontestável. O Estado passa a ter uma função indireta na economia. Sua atuação deve limitar-se ao âmbito social, cuja contribuição para o desempenho econômico é vista como tendo uma importância secundária. No entanto, o processo de mundialização e suas conseqüências sobre a função do Estado parecem melhor colocados quando se considera a importância que este possui para a organização da economia. Na verdade, esta não pode ser pensada de forma autônoma, independente dos aspectos sociais e políticos que constituem elemento central no funcionamento e no desenvolvimento da lógica econômica. Neste sentido, com base na Teoria da Regulação, este artigo apresenta uma interpretação alternativa para o fenômeno da globalização, ou seja, apresenta as formas institucionais ou estruturais desenvolvidas por esta escola, de modo a permitir a análise econômica da mundialização de forma articulada com a esfera social, ressaltando a importância das políticas públicas para o resultado obtido.
\end{abstract}

Palavras-chave: mundialização; Teoria da Regulação; políticas públicas.

A partir dos anos 80, cada vez mais os termos mundialização e globalização têm impregnado o discurso político e acadêmico, determinando e justificando um conjunto de medidas tidas como inexoráveis para que o país esteja apto a fazer face aos desafios próprios do período histórico atual. Este diferenciar-se-ía do regime de acumulação fordista predominante no pós-guerra em razão do enorme desenvolvimento tecnológico, verdadeiro divisor de águas em relação ao período atual. Por um lado, não caberia mais, hoje, a formulação e implementação das políticas nacionais que alicerçaram a construção de economias com base no compromisso entre capital e trabalho (ou arrefecimento das contradições aí existentes), uma vez que estas não permitem os ganhos de produtividade resultantes de uma maior competitividade. Por outro lado, torna-se imperativo flexibilizar as regras contratuais, principalmente aquelas relativas a contratação de mão-de-obra, e diminuir a carga tributária, ao mesmo tempo que as despesas públicas. Em suma, o quadro institucional anterior seria inadequado para assegurar uma melhor inserção internacional no contexto atual, tendo como principal resultado apenas o aumento do déficit público e a criação de entraves ao pleno emprego, conseqüentemente gerador do que se convencionou denominar estagflação.

No entanto, existem diversas nuances nas análises sobre as mudanças em curso. As posições variam da defesa intransigente das livres forças de mercado como única forma de garantir o máximo de bem-estar social, até a tentativa de considerar o Estado enquanto esfera regulamentadora fundamental para suprir as eventuais falhas que o mercado apresente ou, ainda, compatibilizar objetivos políticos e éticos não pertencentes à lógica econômica. Cumpre notar que os pressupostos de tais posições, ou de qualquer das combinações possíveis entre elas, são raramente evocados e nunca contestados como objetivo principal das análises teóricas realizadas - análises que são unânimes no que diz respeito à dicotomia Estado-economia. Embora aceitem em maior ou menor grau a interação entre estas duas esferas, limitam-se a considerá-la como meio de corrigir imperfeições 
de mercado. Na verdade, a ordem econômica é necessariamente instituída a partir da ordem política, e esta, por sua vez, é dependente da primeira. Assim, mais do que estabelecer o papel do Estado frente ao fenômeno da mundialização, pretende-se mostrar, neste artigo, como, e em que medida, ele possui um papel fundamental na instituição e configuração das instituições econômicas (inclusive do próprio mercado), sendo sua atuação fundamental na articulação das formas institucionais próprias a um novo regime de acumulação. Ele é imprescindível na construção e orientação de um regime de acumulação. Mais do que mera instância compensatória das consequiências de um tipo específico de acumulação ou, como na visão liberal dominante, uma esfera que não substitui em hipótese alguma a eficiência do mercado, o Estado tem a função de instaurar a configuração específica de um regime de acumulação e de garantir seu bom funcionamento.

Ao refutar o mito do mercado auto-regulador, a partir do qual se estabelecem as atividades econômicas, a Teoria da Regulação (TR) parece bastante adequada como referencial teórico para a análise econômica atual. Desse modo, apresentaremos, partindo de cada uma das formas institucionais utilizadas como instrumento de análise e com base no desenvolvimento mais recente desta abordagem, uma interpretação sucinta sobre o processo de mundialização. $\mathrm{Ou}$ seja, o padrão de concorrência (item 1), a gestão da moeda (item 2), a relação salarial e o Estado (itens 3 e 4, respectivamente). No item 5 tentaremos ressaltar, embora apenas a título indicativo e utilizando alguns exemplos do caso brasileiro, as implicações em termos de política econômica.

\section{INOVAÇÃO TECNOLÓGICA E O PADRÃO DE CONCORRÊNCIA}

Existem três pontos que bem representam o pensamento corrente. $\mathrm{O}$ primeiro diz respeito à importância da inovação tecnológica, que é tomada como fenômeno autônomo, decorrente da evolução técnico-científica instauradora de um novo padrão de concorrência. O segundo diz respeito ao papel do Estado, tido como secundário nesse processo, ora obstaculizador de seu desenvolvimento, ora como um possível agente para incentivá-lo. O terceiro, na verdade consequiência dos anteriores, trata da autonomização da ordem econômica face aos aspectos sociais e políticos. Contudo, a história do capitalismo, cujo principal elemento é o aumento da produtividade como meio de aumentar ou manter a taxa de lucro, conforme o período do ciclo se encontre num período expansivo ou de crise, tem mostrado o quanto a inovação tem sido uma constante. O que ocorre é que, inegavelmente, há momentos em que ela aparece como elemento preponderante na definição das estratégias das empresas, porém isto se deve mais a uma alteração brusca na trajetória tecnológica em vigor, qualitativamente distinta, do que propriamente na continuidade destas mudanças. $\mathrm{E}$, mesmo assim, as novas tecnologias, que têm aparecido como um fator explicativo no processo de mundialização por conta da intensidade e ritmo que apresentam - comumente mencionados como inéditos se comparados com o período anterior - , são geradas no próprio seio da economia, como resultado das forças de mercado que impulsionaram a busca por maior produtividade. Considerando-se as questões internas à empresa, as novas tecnologias surgem a partir da necessidade de diminuir o tempo morto compreendido na cadeia de produção de tipo fordista. Esta implicava, a partir de certo nível de produção, uma perda em razão da rigidez da cadeia de produção. A introdução de novas tecnologias (controles numéricos, controladores lógico-programáveis, etc.) permite tanto uma maior flexibilidade da linha produtiva, possibilitando alterações rápidas na especificação do produto final, quanto um maior aproveitamento do capital instalado, cujos componentes são comuns às diversas mercadorias, portanto uma adequação constante da produção ao perfil da demanda.

Se é inegável a contribuição das novas tecnologias e, em igual medida, das modernas formas de organização relativas à gestão da mão-de-obra, aos mecanismos de coordenação das atividades ${ }^{1}$ internos de cada empresa e às novas técnicas de comercialização, tal como a franchise e a terceirização, estas se apresentam mais como resultado de um padrão de concorrência do que como elemento externo à forma de articulação e ao estágio de desenvolvimento do capital industrial e comercial. Além disso, uma vez implementadas tais 'inovações', os velhos e conhecidos mecanismos concorrenciais continuam a prevalecer. As barreiras à entrada das empresas concorrentes, a diferenciação dos produtos e a extensão do padrão tecnológico aos demais setores e mercadorias constituem o movimento principal de apropriação de renda. Trata-se mais de explorar, até as últimas conseqüências, a possibilidade aberta pelo novo padrão tecnológico do que de alterá-lo constantemente. Boa parte das mudanças atuais deve-se à expansão das tecnologias de produção e gestão para setores que não as utilizavam. Portanto, o momento inicial em que se impõe a trajetória, no interior da qual se desenvolverá tal processo, deve ser relativizado enquanto mecanismo propulsor do movimento. As inovações correspondem a um estágio bem definido da oferta e da demanda. A estrutura de oferta, ao esgotar as possibilidades de valorização do capital, impôs mudanças no padrão de acumulação, tornando inadequada a demanda baseada no consumo de massa. Doravante, a segmentação do mercado coloca-se como exigência para o aumento do consumo. A produção de uma gama de produtos variados por uma mesma linha de produção, decorrente da maior flexibilização da produção e da gestão administrativa, requer um perfil variado de consumidores. Substituiu-se, assim, a produção em série grande quantidade de um mesma mercadoria - pela produção diversificada - pequenas quantidades de mercadorias diferenciadas, mas que totalizem uma grande produção final.

Mesmo o grande desenvolvimento das empresas transnacionais é conseqüência do tipo de atuação do que outrora se denominava multinacionais. A nova trajetória tecnologica é mais resultado do que propriamente a causa. Pela ótica do mercado, conforme descrito acima, encontra- 
se a gênese do processo de mundialização nas restrições de oferta e demanda - necessidade de diminuição do tempo morto e diversificação da demanda; pela ótica das empresas, o novo padrão de acumulação tem como explicação primeira a necessidade que estas tiveram de alargar seus horizontes de exploração de mais-valia. O que torna mais rico este enfoque é o fato de ressaltar o papel que diversos Estados tiveram para tal evolução - as mudanças observadas estão intimamente ligadas à atuação deles segundo interesses de suas principais empresas. No âmbito externo, as políticas mais agressivas de liberalização levadas a cabo pelos EUA e pela Inglaterra no início dos anos 80, e a maior pressão de organismos internacionais como Banco Mundial (BIRD), Acordo Geral de Comércio e Tarifas (GATT), Banco Interamericano de Desenvolvimento (BID) e Fundo Monetário Internacional (FMI), ao longo de toda a década, são indissociáveis da expansão das empresas transnacionais. Na verdade, o suporte político-institucional neste processo é não apenas representativo, mas constitutivo do movimento de globalização. ${ }^{2} \mathrm{O}$ maior intercâmbio internacional permitiu que as empresas contassem com mercados emergentes, fornecendo-lhes uma flexibilidade considerável de atuação estratégica. Neste sentido, é representativo que, segundo dados da Organização Para a Cooperação e Desenvolvimento Econômico (OCDE), mais de $40 \%$ do intercâmbio internacional ocorre intra-empresas, demonstrando, em certa medida, a abrangência limitada das benesses da mundialização.

Em termos do padrão de concorrência em vigor nas diversas economias, o papel do Estado não é menos importante. De fato, foi o esgotamento do regime de acumulação anterior que forçou mudanças na organização interna das empresas e na relação delas com o mercado. Contudo, é importante levar em conta que tais mudanças são instituídas pela esfera político-institucional. Isto é, se as contradições do regime de acumulação fordista acabaram por comprometer sua própria continuidade, não só muitas das mudanças observadas a partir de então foram orientadas segundo critérios e parâmetros definidos por fatores políticos mas tal "ingerência" foi fundamental para instituir, garantir e permitir o desenvolvimento da esfera econômica sob formas diferentes das anteriores. A TR define como "sistema social de inovação" ${ }^{3}$ o conjunto de disposições institucionais responsáveis pela criação, adoção e difusão das inovações. Em linhas gerais, pode-se sistematizá-lo em dois grupos. $\mathrm{O}$ primeiro, referente às disposições que claramente não pertencem à lógica do mercado. São alguns exemplos o sistema educacional, as condições em que a pesquisa básica é empreendida e/ou financiada pelo Estado, a forma como é implementada a lei de patentes, que incentiva o setor de pesquisa e desenvolvimento das empresas privadas, a infraestrutura necessária para a adoção de determinada trajetória tecnológica, etc. O segundo grupo refere-se às normas que regulamentam o mercado e são responsáveis pelo que se pode denominar como externalidades. São alguns exemplos a estrutura fiscal, que pode beneficiar os setores de bens e de equipamentos com maior possibilidade de incorporar novas tecnologias e, assim, difundir os ganhos de produtividade para o restante da economia, a legislação em vigor, que pode ou não resultar numa relação salarial que incentive o processo de aprendizado no interior das empresas (item 3), e as medidas ligadas ao aumento do nível de consumo, pois possibilitam melhorias na tecnologia utilizada em razão do grande números de usuários, como é o caso dos equipamentos de telecomunicações e informática.

Portanto, o padrão de concorrência e a configuração particular que ele assume em cada sociedade são resultados do tipo de regulação empreendida pelo Estado. Isto não só em termos internos, mas também no tipo de suporte que ele representa para as principais empresas frente à concorrência internacional. O termo globalização muitas vezes deixa de lado esta dimensão do problema, que não pode ser considerada algo novo para o capitalismo. O apoio do Estado, diretamente ou através das agências e instituições internacionais, é peça central para a compreensão do processo de reestruturação econômica.

\section{O MERCADO FINANCEIRO}

Em certa medida, o mercado financeiro tem sido tomado como caso paradigmático do processo de globalização. As razões disto decorrem do fato de que, além de vetor de mudanças nas principais economias e na relação entre elas, ele incorpora de forma clara os diversos elementos que determinaram a mundialização. Em primeiro lugar, porque é incontestável que seu avanço se deve fundamentalmente à necessidade de gerar oportunidades de apropriação de renda. Em segundo lugar, porque a revolução tecnológica é fator crucial para a compreensão das novas formas de criação e gestão dos ativos financeiros. $\mathrm{O}$ ritmo de criação e inovação observado nos produtos financeiros, e consequentemente o aumento do fluxo internacional de capitais, está intimamente ligado às novas tecnologias. Além disso, para explicar tal desenvovimento, é preciso considerar que, por um lado, a mundialização financeira contou com o suporte dos Estados da tríade, consubstanciados nas respectivas políticas monetária, fiscal e cambial, a partir da derrocada do sistema de Bretton Woods; por outro lado, a própria formação e as mudanças observadas neste segmento são resultados de um conjunto de medidas institucionais de natureza não exclusivamente econômica, sujeitas a critérios que contemplam objetivos eminentemente políticos e, portanto, condicionadas a finalidades preestabelecidas segundo uma lógica que nada tem a ver com a racionalidade de mercado, conforme afirma o discurso hegemônico.

Quanto ao primeiro ponto, o grande fluxo de capitais remonta ao final da década de 60 e início da de 70 . Pelo lado da oferta, a abundância de capitais devia-se ao excesso de liquidez do sistema financeiro, decorrente do desenvolvimento do mercado de eurodólares e, posteriormente, de petrodólares. Pelo lado da demanda, o período denominado de estagflação implicava a diminuição de oportunidades de reinvestimento no setor industrial, isto é, os lucros auferidos foram depositados nas principais praças financeiras, aumentando em muito o poder de criação de moeda de crédito por parte dos bancos. Num primeiro momento, o financiamento dos déficits orçamentários, típicos 
do regime fordista, e os empréstimos aos países do Terceiro Mundo foram uma importante alternativa de aplicação destes recursos, porém o próprio serviço das dívidas, sob a forma de juros cada vez mais elevados, reforçava a supremacia da esfera financeira. Atualmente, os recursos disponíveis em ativos financeiros ultrapassam em muito a riqueza real (segundo dados do Banco de Regulamentação Internacional, BRI, apenas $8 \%$ das transações no mercado de câmbio em 1995 correspondem a transações de produto real).

Quanto ao segundo ponto, além da disponibilidade abundante de recursos, em razão da baixa rentabilidade do setor industrial, o sistema bancário introduziu uma variedade de procedimentos - câmara de compensação automática, transferência eletrônica de fundos, contas de depósitos convertíveis em diferentes produtos financeiros, entre outros - que dificultaram em muito o controle da expansão dos meios de pagamento pelos bancos centrais. Assim, houve não só um enorme acréscimo do capital fictício mas, também, este acabou por impor e reforçar uma regulação monetária baseada nos interesses dos credores. $\mathrm{O}$ modo de regulação anterior, baseado no crédito e nas baixas taxas de juros, passou a ser pautado pelo mercado de câmbio e altas taxas de juros.

No entanto, em relação ao terceiro ponto, se o monitoramento dos agregados monetários tornou-se bem mais difícil, dada a imprevisibilidade e a rapidez com que os fenômenos monetários e financeiros se reproduzem, a importância das políticas empreendidas pelo Estado não perderam espaço. $\mathrm{O}$ aumento do fluxo de capitais que se seguiu não teria sido possível sem que as políticas de desregulamentação fossem empreendidas. De fato, a liberalização financeira é parte integrante do processo. Ela facilitou o movimento de capital especulativo entre os diversos países e permitiu que as diferentes instituições financeiras, antes com funções bastante específicas, segundo a natureza do mercado em que atuavam (bancos comerciais, bancos de investimento, bolsas de valores, corretoras de câmbio e valores, etc.), passassem a dispor de uma flexibilidade muito maior. Em muitos casos é difícil diferenciar, hoje, o campo específico de uma instituição particular, mesmo quando esta não faz parte de um conglomerado financeiro. Além disso, a gestão da moeda ainda continua a cargo das autoridades monetárias de cada país. O mito de uma regulação monetária totalmente privada é inviável, tanto do ponto de vista teórico quanto empírico, uma vez que somente a atuação de um banco central pode, através de sua atuação discricionária como emprestador em última instância, assegurar a emissão privada de moeda de crédito contra o risco de crise sistêmica do sistema. Uma compensação privada dos meios de pagamento acarretaria uma expansão monetária exclusivamente orientada pelos critérios de rentabilidade e lucro das instituições financeiras, trazendo, consequientemente, a possibilidade de quebra generalizada de confiança no sistema financeiro. Mesmo que este não fosse o caso, o comportamento dos investidores sobre condições de extrema incerteza, ou por conta de um crescimento desmesurado do valor dos ativos na tentativa de aumentar a apropriação de mais-valia financeira, provocaria o mesmo resultado. O krach em 1987, nos EUA, a crise ocorrida nos bancos japoneses no período 1990-1991 e, mais recentemente, a crise mexicana em 1994, são alguns exemplos. Afinal,

"como unidade de conta e meio de pagamento, a moeda
possui o papel de bem público. É a base dos contratos que
dá às mercadorias o direito de propriedade e de crédito (...)
Decorre daí a dualidade entre a criação privatizada de
moeda a as funções coletivas já mencionadas: garantir a
âncora nominal e prevenir o risco de sistema. Estas funções
são assumidas por uma instituição especial - o banco
central -, embora ele não tenha o controle da maior parte
da criação monetária." (AGLIETTA, 1994, p.96 - traduzi)

Portanto, se é inegável que a globalização financeira aproximou muito os sistemas financeiros, eles continuam a desenvolver-se de acordo com interesses nacionalmente determinados. Um bom exemplo, é que apenas uma parte dos ativos financeiros de um país, incluindo as inovações mais recentes, é cotada ou tem condições de ser colocada no mercado internacional.

Além disso, a possibilidade de crises sistêmicas é constante. $\mathrm{O}$ sistema financeiro constitui-se em importante alavanca para o crescimento econômico, dada sua posição privilegiada para avaliar os riscos e possibilidades de investimento de risco mais elevado, como é o caso dos que se destinam à inovação tecnológica; porém, ele também pode criar movimentos altamente especulativos, em razão das expectativas dos principais investidores de mercado ou do tipo e quantidade de financiamentos concedidos e considerados duvidosos a partir de um dado momento. Este argumento torna-se mais importante quando consideramos que é decorrente das próprias forças de mercado. Ou seja, dadas as características intrínsecas da moeda, é imprescindível a dimensão pública da gestão monetária, e os parâmetros em que se apoia não são explicados apenas por critérios técnicos. Dentre as diversas combinações entre os níveis de taxas de juros, de câmbio e de expansão monetária, não existe, a priori, um ponto ótimo a ser alcançado. Os resultados possíveis são inúmeros e dependerão dos efeitos das variáveis monetárias (nem sempre no mesmo sentido) sobre cada segmento industrial, sobre o nível e tipo de consumo e sobre as contas públicas. Por conseguinte, a escolha obedece a critérios não decorrentes da lógica do mercado impessoal e onisciente, e hierarquizam os beneficiários das medidas empreendidas. Neste sentido, a política monetária a cargo do Estado coloca-se como fator crucial para incentivar o financiamento das atividades que gerem a inovação tecnológica ou que nela estejam apoiadas, permitindo o crescimento econômico de acordo com as exigências postas pelo novo padrão de concorrência.

\section{A RELAÇÃO SALARIAL}

A relação salarial em vigor em cada regime de acumulação historicamente determinado, ao incorporar a razão produtividade/salário expressa as possibilidades de compatibilizar produção e demanda. Portanto, ela tanto é componente fundamental de todas as crises do capitalismo 
quanto responsável pelas regularidades que se apresentam. O regime concorrencial, por exemplo, deparava-se com crises cíclicas causadas pelo fato de que o crescimento da produtividade era maior do que a variação dos salários, sem que os rentistas ou o Estado formassem uma terceira demanda. O período fordista, por sua vez, a partir da crise estrutural de 1929 e do acirramento das lutas sociais e sindicais, estabeleceu a compatibilidade entre oferta e demanda através da política de gastos públicos e do aumento do salário de acordo com o crescimento da produtividade. ${ }^{4}$ Nos tempos atuais, o esgotamento do regime fordista não implica menor importância da relação salarial. Embora mais complexa, ela é ainda mais importante na configuração institucional específica que cada economia estabelecerá frente ao processo de mundialização em curso.

Pelo lado da demanda, o conjunto de regras e convenções que determinam os níveis de salários e de emprego tem de ser compatível com a necessidade de consumo necessário à realização da mais-valia, incorporada em produtos com valor agregado crescente. Se a estrutura de oferta é cada vez mais diversificada, as economias de escala continuam sendo um imperativo para a implantação de determinadas linhas de produção. As novas tecnologias de produção permitem maior flexibilidade em relação ao produto final, porém a quantidade final do total de produtos, dados os altos custos fixos envolvidos, tem de ser grande para assegurar a viabilidade econômica do projeto. Pelo lado da oferta, a importância da relação salarial adquire uma função estratégica. A criação, a adequação e o ritmo de difusão das novas tecnologias estão intimamente ligados ao nível de salário. Sendo assim, a remuneração dos trabalhadores e a organização do trabalho no interior das empresas é que permitirão maior ou menor empenho no cumprimento das tarefas. Afinal, se são as restrições de "mercado" que lançaram as empresas na busca por novos produtos e maior produtividade, este objetivos são alcançados na medida em que a remuneração e as condições de trabalho incitem o processo de aprendizagem pela prática e sua generalização no interior da empresa. Mais importante ainda é que o tipo de configuração da relação salarial vigente numa economia tornará interessante ou não a adoção de estratégias inovadoras por parte da classe capitalista. Assim,

\footnotetext{
"Se os assalariados são pouco organizados, até mesmo sem organização, a legislação social quase inexistente, a duração da jornada elevada e os salários mantidos a um nível baixo, as empresas não serão incitadas a desenvolver inovações economizando massivamente o trabalho: tal é uma das origens de uma acumulação essencialmente extensiva por ocasião, por exemplo, das primeiras revoluções industriais. Se, ao contrario, os assalariados defendem seus interesses por meio de sindicatos fortes, se o direito do trabalho reconhece as restrições do livre jogo das forças de mercado, se as lutas sociais impõem uma redução na duração do trabalho, e se a penúria de mão-de-obra e/ou as reivindicações sindicais induzem aumento de salários e sua antecipação induz à busca de crescimento a longo prazo, então as inovações tecnológica e organizacional tornam-se um elemento essencial da estratégia das empresas e, desse modo, conseqüência do modelo de crescimento." (AMABLE et al, 1997, p.121 - traduzi)
}

Colocando em outros termos, as modernas teorias de capital humano e de salário-eficiência, que têm justificado algumas das medidas empreendidas pelos governos e/ou empresas, encontram certo respaldo na medida em que valorizam a importância de fatores outros que o simples valor pecuniário percebido pela força de trabalho. O grau de instrução resultante do sistema educacional e políticas salariais que consideram que a razão produtividade-salário é resultado do conjunto de condições oferecidas pelo capital são alguns exemplos. No entanto, a abordagem da TR vai um pouco além. O trabalhador é considerado na perspectiva de capital humano porque o savoir faire, necessariamente, nele está incorporado, como portador de trabalho que é, agente fundamental para a criação, adoção e difusão de inovações tecnológicas. A similitude termina quando se considera que, diferentemente da interpretação neoclássica, os níveis de salário e de emprego e a distribuição de renda não são determinados pelo mercado de trabalho. Tais variáveis resultam do tipo de compromisso institucional entre as empresas e o mundo do trabalho, determinado em grande parte pela regulação empreendida pelo Estado, em consonância com aspectos históricos e sociais de uma sociedade em particular. A relação salarial compreendida como conjunto de normas e convenções, não reduzíveis ao mercado de trabalho, põese assim como principal fator na construção de um círculo virtuoso que possa fazer face aos desafios impostos pela crise do regime fordista.

\section{A AUTONOMIA RELATIVA DO ESTADO}

O Estado apresenta-se como outra importante forma institucional, junto com o padrão de concorrência, a gestão da moeda, a relação salarial e o tipo de relação internacional vigente. Sua importância se deve ao papel desempenhado na configuração estabelecida das demais formas institucionais, conforme já explicitado, mas que também possui uma autonomia relativa. Ou seja, a ordem política obedece a uma lógica própria, não deduzida somente das funções econômicas a seu encargo, mas, paradoxalmente, determinando-as e por elas sendo determinada. Uma crise pode ser decorrência das contradições econômicas geradas pelo (e ao longo do) regime de acumulação em vigor. Do mesmo modo, as razões de uma retomada do crescimento, a instituição de uma nova configuração econômica ou o aprofundamento da crise podem ser eminentemente políticos. Portanto, quando se concebe o Estado como uma relação social no interior da qual o aspecto político pode estar ou não em consonância com os interesses econômicos, as questões exclusivamente políticas são um aspecto a mais a ser considerado.

Nesse sentido, o Estado nem é tomado como esfera acima da sociedade, imune aos interesses de classe, nem é tomado como esfera a partir da qual a classe dominante obrigatoriamente imponha todos os seus interesses, ou ainda exclusivamente como resultado da correlação de forças 
econômicas em seu interior. Sua gênese não é derivada do capital, segundo a visão marxista mais comum, nem da somatória dos interesses individuais, conforme prega a visão positivista, como exposto por Théret:

\begin{abstract}
"Neste nível, conceber o Estado como uma relação social é, então, segundo nossa interpretação, negar que ele seja apropriado, definindo-o dessa forma a partir de seus aparelhos, ou, contrariamente, antropomorfizá-lo, considerando-o como um simples sujeito sem base material própria. Porém, significa também renunciar a uma definição do Estado tendo a priori as funções sociais vis-à-vis a uma exterioridade que lhe é própria. O Estado não estaria imediatamente subordinado a uma infraestrutura, como por exemplo o capital ou a sociedade civil, mas reduzido a uma 'super-estrutura'. É, ao contrário, conferir-lhe o mesmo status conceitual do capital na teoria marxiana e vê-lo como uma relação segundo a qual se confrontam os agentes sociais (homens e grupos) no contexto de um certo processo de 'trabalho político' (processo este que, no seu conjunto, serve à dominação), onde são engajadas forças humanas ativas e meios materiais, e onde se desenvolve a apropriação/ expropriação de meios políticos e de reprodução social." (THÉRET, 1992, p.35 - traduzi)
\end{abstract}

Segundo esta abordagem, a diversidade de configurações resultantes da interação entre os aspectos políticos e econômicos tende a ser igual ao número de casos existentes. Cada sociedade apresenta uma infinidade de particularidades institucionais, sociais e econômicas, mas se a forma como estas serão articuladas está condicionada por determinantes econômicos, produção e acumulação de capital, ela também está sujeita à necessidade de produzir e acumular direitos políticos. A partir daí, a incompatibilidade entre os interesses políticos, econômicos e o conjunto de instituições coloca-se como uma possibilidade real, principalmente nos momentos de crise, resultado do desenvolvimento das contradições geradas no regime de acumulação anterior.

Além da possibilidade de crises, de seu aprofundamento ou do aumento da sua duração, esta análise ressalta a interação obrigatória entre as ordens política e econômica. Isto é, se a ordem econômica necessita do suporte institucional para garantir a produção e a acumulação de valor, a ordem política necessita dos recursos providos pela primeira a fim de manter sua legitimidade e, portanto, produção e acumulação de poder político. É o regime fiscofinanceiro que estabelece esta interação, uma vez que o Estado depende do crédito concedido para realizar suas despesas. À arrecadação fiscal se soma a receita obtida pela venda de títulos e a possibilidade de financiamento pela emissão da moeda central. Portanto, para a iniciativa privada, a emissão de moeda de crédito garante a liquidez necessária para assegurar o nível de investimento, determinado pela expectativa de receita futura e o estado de confiança, conforme formulado por Keynes; para o Estado, são as possibilidades de emissão de moeda central e títulos que determinam o montante de receita antecipada disponível para financiar os gastos públicos presentes, garantindo a produção e acumulação de direitos políticos. Segundo Théret, "o Estado fiscal, a forma econômica do Estado, é apenas uma forma secundária e não matricial, ao contrário do que prevalece no modo industrial de acumulação capitalista, onde é a forma econômica produtiva do capital que é essencial. Evidentemente, isto reflete que na acumulação política acumula-se para gastar, enquanto que na acumulação econômica gasta-se para acumular. Portanto, essa inversão de polaridades funcionais tem uma conseqüência lógica muito importante: ela lembra que o Estado funciona à base de crédito (...) O Estado deve, então, benficiar-se ao mesmo tempo de crédito quanto da capacidade de impor sua soberania e de uma confiança baseada no fato de que não utilizará seu poder soberano de forma ilegítima". (THÉRET, op. cit, p.134-135 - traduzi)

\section{POLÍTICAS ECONÔMICAS}

Do exposto podemos tirar algumas conclusões, apesar de ainda em caráter indicativo. A primeira, é que os gastos públicos, ou o aumento destes segundo critérios exclusivamente políticos, fazem parte da própria lógica do sistema. Eles não se limitam à receita arrecadada através de impostos e taxas, tendendo inclusive a ser bem maior. $\mathrm{Na}$ realidade, é preciso que o nível de gastos seja crescente, pois o poder político se baseia na capacidade que tem em criar e distribuir novos direitos. O regime fisco-financeiro, baseado no crédito privado concedido através do open market, permite a antecipação de receita necessária. Uma política econômica não pode deixar de levar em consideração que as despesas de cada governo obedecem a uma lógica totalmente diferente dos ditames da racionalidade econômica neoclássica; e a elas não deve ser identificada, em razão de que a legitimidade política, em inúmeros casos, é obtida a partir de meios e finalidades que podem contradizer os interesses de curto e médio prazos da acumulação de capital. Atualmente, no Brasil, as políticas sociais direcionadas segundo as necessidades prementes de larga camada da população - como os programas de renda mínima, cesta básica e ajuda de emergência aos mais necessitados constituem-se bons exemplos. Mais do que simplesmente "governar a miséria" em caráter provisório, trata-se de estratégia permanente de política, levada a termo como forma de produção e distribuição de direitos, portanto de legitimação dos sucessivos governos. O que não quer dizer, como se verá a seguir, que cheguem a contribuir para um regime mais justo.

A segunda conclusão é que esta utilização do "econômico" pela ordem política não exclui o seu contrário - a instrumentalização política pela ordem econômica. Como visto, a definição da trajetória tecnológica requer uma participação ativa do Estado. Pelo lado da oferta, ele deve garantir as condições mínimas de incentivo à inovação tecnológica: não só pela pesquisa básica e qualificação da mão-de-obra, resultante do nível de educação, mas também através de uma política industrial que coordene e incentive os setores com maior potencialidade de modernização. As variáveis preço e quantidade não definem um ponto de equilíbrio único ou a qualidade do produto final, como querem os apologistas das leis de mercado. ${ }^{5}$ São os fatores 
institucionais que determinam a configuração específica do padrão de concorrência em vigor. Além disso, dado o papel estratégico dos bancos no financiamento das unidades produtivas, a regulação monetária a cargo do banco central coloca-se como instrumento imprescindível para se atingir o objetivo desejado. Falta de liquidez, altas taxas de juros, câmbio sobre-valorizado, ou uma combinação particular destas variáveis, podem mostrar efeitos nefastos para a economia. Pelo lado da demanda, o tipo de relação salarial cumpre papel fundamental. Ela tanto incentiva uma demanda de bens de capital, elevando a produtividade do sistema, como assegura a realização do valor incorporado nas mercadorias a serem vendidas. No entanto, o caso brasileiro, neste aspecto, é singular. Os altos índices de concentração de renda, a política de contenção da demanda como meio de controlar a inflação e a flexibilização das leis trabalhistas, cujo resultado é a precarização das condições de trabalho, apontam no sentido contrário. A tendência observada na década de 80 parece se reforçar na maior parte das mudanças atualmente preconizadas para o mercado de trabalho. Neste período, segundo dados da Pesquisa Nacional a Domicílio (PNAD), o aumento na desigualdade de renda deveu-se também ao crescimento do emprego assalariado sem carteira assinada, do emprego com carteira assinada mas de baixa qualificação, às altas taxas de rotatividade, que pressionam os salários para baixo, e à expansão do trabalho por conta própria dos estratos de renda mais elevada. As modernas técnicas de gestão (just in time, terceirização, qualidade total, etc.) parecem ter sido utilizadas mais como forma de disciplinar o mundo do trabalho do que de introduzir as condições para a inovação e difusão de inovações com base na experiênciă do trabalhador. ${ }^{6}$

A terceira conclusão que se pode tirar desta abordagem, corolário das duas primeiras, é que a gestão econômica e a gestão política são complementares entre si. O tipo de regulação pode ou não criar condições de retomada do crescimento, com efeitos positivos ou negativos sobre os níveis de emprego e renda. Nesse sentido, os gastos do governo assumem uma dimensão estratégica fundamental para a criação de um círculo virtuoso de crescimento. Se o déficit público tem sido apontado como um dos principais empecilhos para a retomada do crescimento, em geral esquece-se que sua magnitude é bem menos importante do que o efeito que as despesas provocam na sociedade como um todo. Elas têm o objetivo de legitimar o governo e podem ser empreendidas, por exemplo, com vistas a melhorar as condições de vida imediata da parcela da população que vive precariamente. À parte os benefícios sociais, e para nos atermos exclusivamente aos mecanismos econômicos, o importante é o efeito que o financiamento dessas medidas terão sobre a estrutura da dívida pública. Um nível de gastos elevado no período anterior implica uma quantidade de títulos suficientemente grande para que, em determinado momento, o governo possa emitir novos títulos, garantindo aos investidores condições de lastro seguro para os investimentos financeiros, sem prejudicar o nível de liquidez indicado como adequado pela emissão de moeda de crédito do sistema bancário. Essas ocasiões são particularmente importantes e comuns nas condições atuais, dado que a mundialização aumenta a incerteza e a preferência pela liquidez. No caso contrário, a contenção de despesas por parte do governo leva a um círculo vicioso, de aumento da dívida como contrapartida da falta de liquidez. O controle monetário restritivo aumenta a taxa de juros, diminuindo os investimentos e comprometendo parte da dívida pública, cuja rolagem fica mais cara. É claro que este efeito sobre a estrutura da dívida pública e, conseqüentemente, sobre os graus de liberdade da política monetária, tem de ser acompanhado de uma relação salarial que incite a inovação e garanta a demanda, bem como de uma atuação do governo sobre o padrão de concorrência a ser instituído conforme exposto anteriormente. A partir daí a ordem econômica teria seus interesses resguardados, criando-se o tipo de compromisso e o grau de confiança necessários para a retomada do crescimento econômico.

O que torna o problema particularmente difícil é a herança que o Brasil traz do regime de acumulação anterior. De fato, o fordismo periférico se caracterizou por um crescimento com concentração de renda sem precedentes. Isto conduz a tentativas constantes, por parte da elite econômica, de impor um novo regime sem que sejam consideradas outras questões que as valorizadas por uma visão de curto prazo. A privatização sem critérios transparentes, a abertura comercial acelerada e, até mesmo, a aceitação de políticas sociais sob a condição de que tenham pouco ou nenhum impacto sobre as despesas são excelentes exemplos. Este processo é facilitado pelo fato de que se o processo de mundialização foi decorrência da diminuição da taxa de lucro na esfera produtiva durante o final da década de 60 e início da de 70 , ele tem o sistema financeiro como principal vetor dos interesses do capital. As dívidas externa e interna constituem-se então um ponto de fragilidade importante para a aceitação de critérios políticos pela ordem econômica. No entanto, permanece a importância, para a ordem econômica, do apoio político na construção de um novo padrão de concorrência e gestão da moeda. Enfim, a menos que se queira construir um pósfordismo periférico, no sentido de uma distribuição de renda perversa, ainda há autonomia para políticas cujo crescimento econômico se compatibilize com objetivos sociais. A opção é primordialmente de cunho político, e não, como faz crer o discurso liberal, por razões de 'mercado'. Estas, como se procurou explicitar ao longo deste artigo, não se sustentam sem o apoio político e precisam de uma regulação constante por parte do Estado, possibilitando assim a busca de um regime de acumulação menos concentrador de renda do que o anterior. 
${ }^{1}$ Para maiores detalhes sobre a importância na escolha de uma organização interna baseada na coordenação hierárquica ou na coordenação horizontal, bem como suas conseqüências em termos de geração de novas tecnologias, ver AOKI (1994).

${ }^{2}$ Reserva-se aqui o termo mundialização para descrever a totalidade do processo, em que a atuação e o potencial das empresas concorrentes encontram-se diretamente relacionados à infra-estrutura e à atuação política dos respectivos Estados nacionais, enquanto globalização designa apenas a maior interação dos fenômenos econômicos. A este respeito ver CHESNAIS (1994).

${ }^{3}$ Esta denominação é adotada pela TR em substituição a "sistema nacional de inovação", utilizado pelos neo-shumpeterianos, por deixar em aberto a questão do espaço sobre o qual opera tal sistema. (ver AMABLE et al, 1997, p.4)

${ }^{4}$ Para uma descrição detalhada sobre as crises e os regimes de acumulação do modo de produção capitalista, ver MALAGUTI (1994).

${ }^{5}$ A bibliografia sobre equilibrio, de Nash, se bem que desenvolvida tendo como exemplo o mercado financeiro, é bastante esclarecedora, principalmente quando se considera que as incertezas características daqueles mercados estão também presentes no mercado de bens e serviços, sujeito a inovação constante.

${ }^{6}$ Para maiores detalhes, ver LEITE (1994) e BALTAR \& HENRIQUE (1994).

\section{REFERÊNCIAS BIBLIOGRÁFICAS}

AGLIETTA, M. Ordre monétaire et banques centrales. In: ORLÉAN, A. (dir.). Analyse économique des conventions. Paris: PUF, 1994.

AMABLE, B. et al. Les systèmes d'innovation à l'ère de la globalisation. Paris: Economica, 1997.

AOKI, M. Sur certains aspects des conventions dans l'entreprise. In: ORLÉAN, A. (dir.). Analyse économique des conventions. Paris: PUF, 1994.

BALTAR, P. E. A. \& HENRIQUE, W. Emprego e renda na crise contemporânea no Brasil. In: $O$ mundo do trabalho. CESIT. São Paulo: Página Aberta, 1994.

CHESNAIS, F. La mondialisation du capital. Paris: Syros, 1994.

LEITE, M. P. Reestruturação produtiva, novas tecnologias e novas formas de gestão da mão-de-obra. In: $O$ mundo do trabalho. CESIT. São Paulo: Página Aberta, 1994.

MALAGUTI, M. L. A teoria da regulação: dialogando com Karl Marx. In: MENDONÇA, J. P. et al (orgs.). Crise ou regulação: ensaios sobre a teoria da regulação. Vitória: Ed. FCAA, 1994.

THÉRET, B. Régimes économiques de l'ordre politique. Paris: PUF, 1992. 